
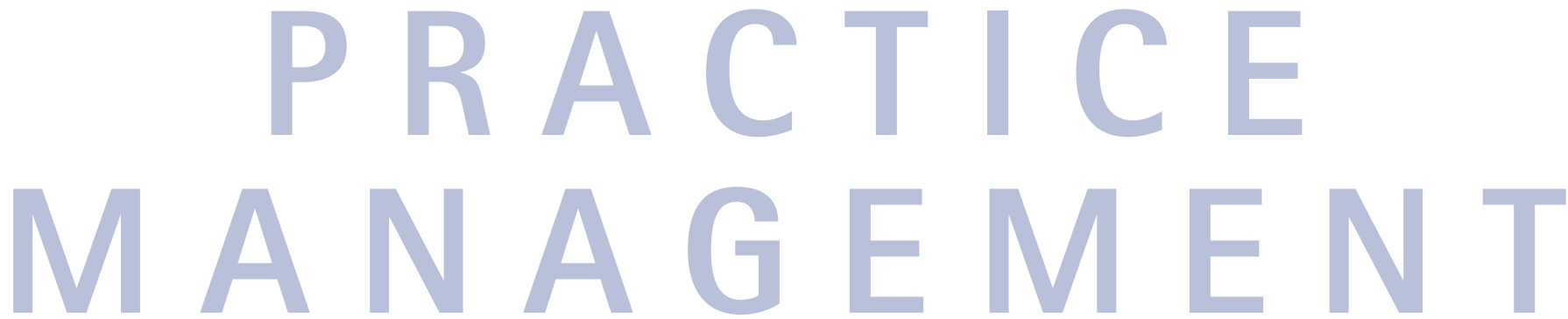

\title{
Remind your patients with DentalText
}

DentalText is a web-based tool designed exclusively for the UK dental industry. It is designed to remind patients of impending appointments and thereby reduce costly missed appointments for your practice. By signing up to DentalText, dental professionals will be able to send their patients reminders and improve patient communications simply and effectively, by using text messages.

DentalText is easy to sign up to. Just visit www.dentaltext.org.uk, create your account and log in to type your SMS text message. Click send and the message is delivered - it's as simple as that. Messages are charged at $10 p$ per text, paid for in advance, and discounts are available for high volumes of messages. For more information or a free demonstration, please call 08701162333 or email sales@dentaltext.org.uk.

Reader response number 56

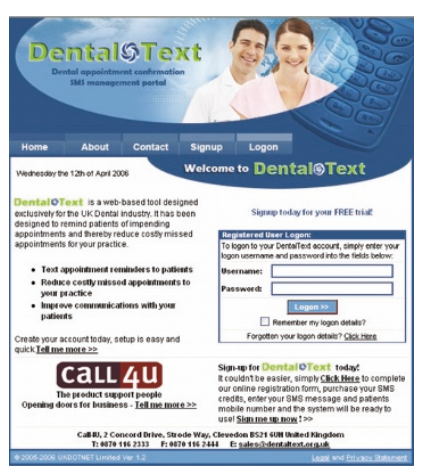

\section{Ease of integration}

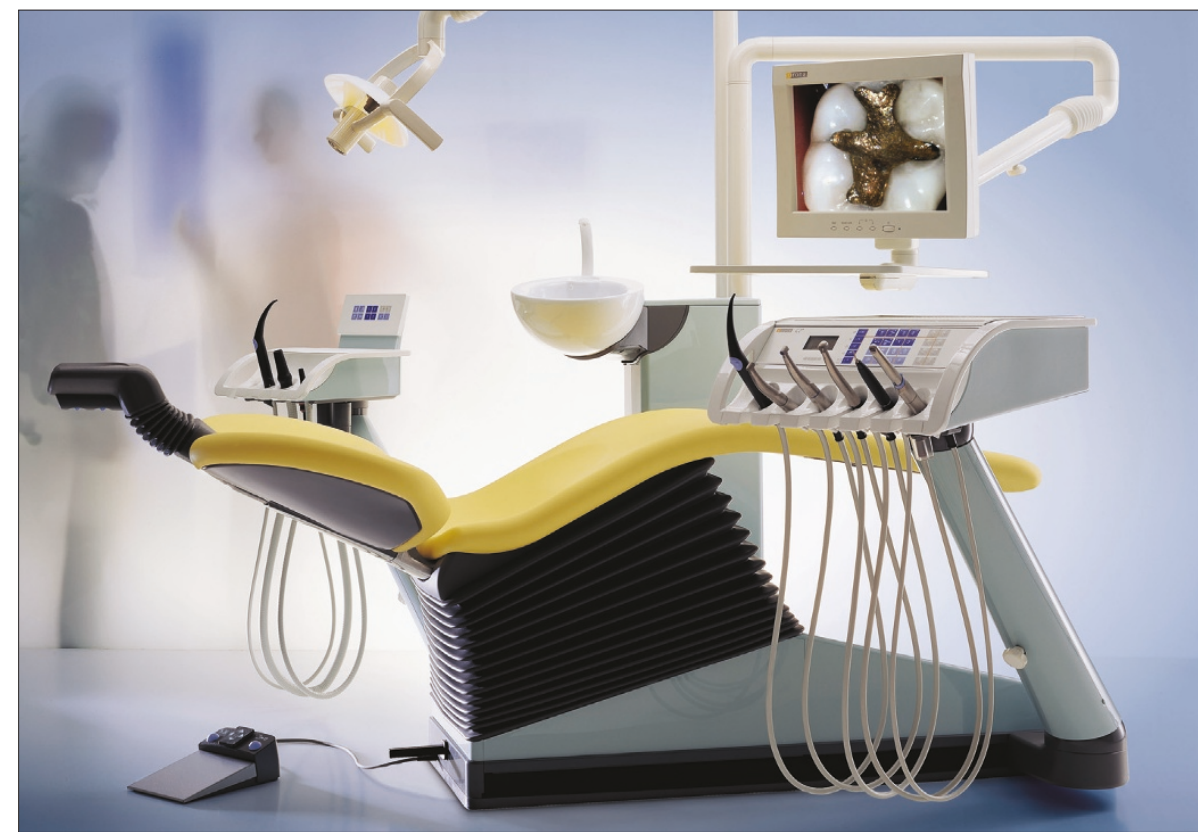

Sirona's C+ range of treatment centres is designed to maximise flexibility, integration and technology within the dental practice, creating a seamless workflow that optimises productivity. With an unrivalled design and a multitude of options, configuring the treatment centre for your specific needs has never been easier.

Integration into the surrounding dental environment is simple and sophisticated. By networking your entire practice through the treatment centre's integrated patient communication system, it becomes the hub for patient education, displaying digital radiography, scheduling and even entertaining.

Superior engineering and craftsmanship allow the C+ delivery unit to integrate all the key dental instruments into an ideal practice solution. Control of a three-way syringe, air or electric handpieces, intraoral camera, prophylaxis, ultrasonic scaler and LED curing light is accomplished through a single footswitch.

For more information please contact Sirona Dental Systems on 08450715040. Reader response number 55

\section{Find a new dimension}

Designer Dental can bring a whole new dimension to your practice marketing, promotion and professional profile. Their experienced in-house team is friendly, flexible and efficient and can deliver everything you need to enhance your public image.

All practices are different and the team at Designer Dental will work to create solutions tailored to your individual requirements and aspirations. Ideas come to life in their newly equipped and refurbished design studio The Den, where in- house designers deal with all aspects of creative ideas and design. This can be the difference between literature and exceptional literature.

If you're seeking an experienced and enthusiastic marketing company providing excellent value for money and working solely within the dental profession, Designer Dental are just what you're looking for. For more information contact Designer Dental on 01642206106 or visit www.designerdental.co.uk.

Reader response number 57

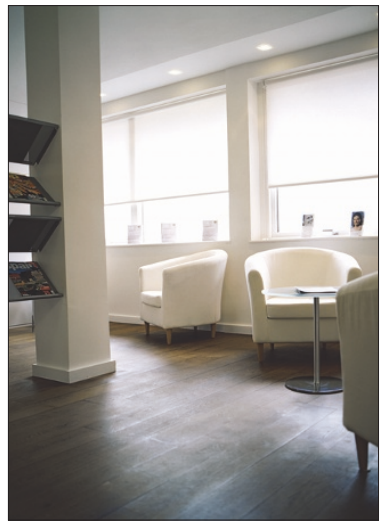

